forensic photography does not lend itself to fame. As legal evidence, the photographs that Reiss took in the service of the law would have fallen foul of that same law had they been published at the time, and until now the images in this exhibition have remained inaccessible to the public. Now, the authorities have decided to release them, even though a grandchild of one of the victims - or of one of the perpetrators - could still wander innocently into the exhibition and have a fright.

Seeing the photos alongside Reiss's notes - on the importance of recording the precise position of the corpse, for example, or on people's susceptibility to autosuggestion when it comes to judging physical resemblance - you are struck by how modern his thinking was. At the time, when the science of photography was still developing, many of the Swiss houses to which he was called had no electricity. A section on the usefulness of tattoos in identification is a powerful reminder of this contrast: the naked torsoes of ex-soldiers are photographed decorated with

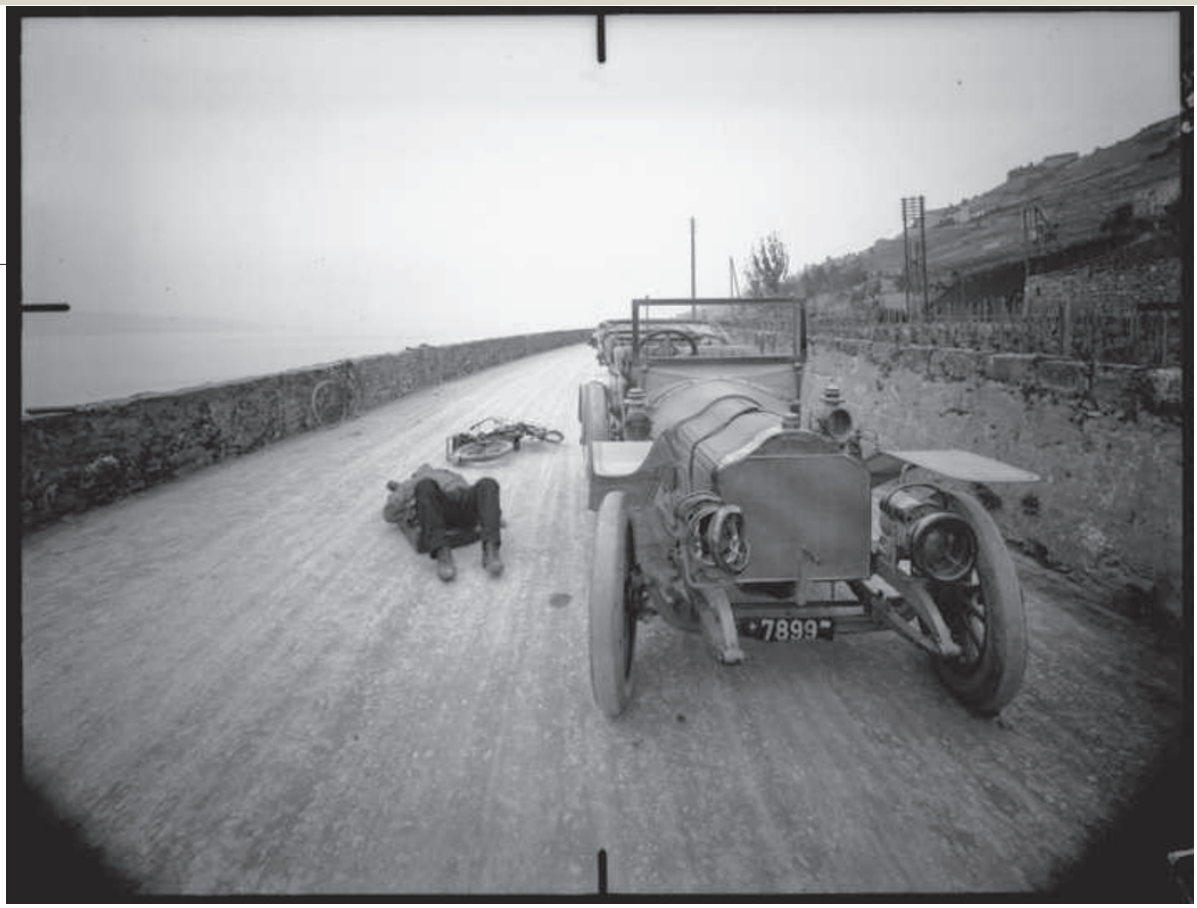

Rodolphe Reiss pioneered the use of forensic photography for recording crime scenes in the early 1900 s.

Edwardian ladies sporting wide-brimmed hats, fully clothed and revealed only from the neck up.

The methods for reading a crime scene may have evolved since Reiss's time, but the reasons for committing murder and the information contained in those scenes have not. Were Reiss to come back to life today, he would no doubt quickly find his feet in any forensic laboratory.

Laura Spinney is a writer based in Lausanne, Switzerland.

\title{
Earliest sketches of the Moon
}

\section{Cosmos and Culture: How Astronomy Has Shaped Our World Science Museum, London Until 30 December 2010}

Amid the commemoration of the Apollo landings, another lunar anniversary has just passed quietly. Four centuries ago, on 26 July 1609, the English scholar Thomas Harriot pointed his recently acquired 'Dutch trunke' at the Moon and drew what he saw.

He thus became the first person to record astronomical observations through a telescope, a few months before Galileo Galilei did the same. But unlike Galileo, who was struggling to feed a family on a lecturer's salary and angling for the patronage of the Medicis, Harriot had made his fortune and had no need of fame. He was already a distinguished mathematician - a renowned algebraist

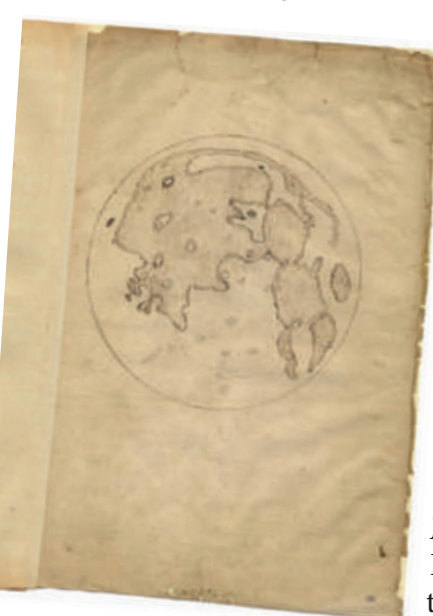

Thomas Harriot's magnified map of the Moon. who had corresponded with Johannes Kepler on the physics of rainbows and who had produced a body of work on the physics of motion.

By 1609 Harriot had other reasons to avoid the limelight. His patron, Henry Percy, Earl of Northumberland, was a cousin of one of the gunpowder plotters who had sought to blow up the English Parliament in 1605, and Harriot himself was imprisoned and interrogated for his connection. His papers were lost after his death in 1621 and not rediscovered until 1784 , still at Percy's estate. So he remains little known.

Two of Harriot's drawings of the Moon, one of which shows its seas and craters, plus his notes on the moons of Jupiter, are on display in London's Science Museum until the end of 2010 as part of the exhibition Cosmos and Culture.

They are accompanied by a first edition of Galileo's Sidereus Nuncius of 1610, a 1496 edition of Ptolemy's Almagest and first editions of Nicolaus Copernicus's De Revolutionibus Celestium Orbum (1543), Kepler's Astronomia Nova
(1609) and Isaac Newton's Principia (1687). Other highlights include Chinese astrological figurines, made during the Tang dynasty in the first millennium $\mathrm{BC}$, and the 2-metre-long telescope through which William Herschel discovered the planet Uranus in 1781.

The exhibition's subtitle is 'How Astronomy Has Shaped Our World'. But any compelling stories that could be told about the way that astronomy forges links between artisan and genius, amateur and professional, royal patron and government agency or pure science and popular culture are lost here through poor display. The fine Harriot drawings cannot be viewed close up, and labels are provided through a touch-screen display that is situated far from the pieces it describes.

Because everything is thrown together in an arbitrary fashion - those mighty books rub shoulders with a pile of sci-fi paperbacks, and the Tang-dynasty figures sit near an astronomical edition of the board game Monopoly this exhibition is both a must-see and a missed opportunity.

John Whitfield is a writer based in London. e-mail: ja_whitfield@hotmail.com

\section{Correction}

In the book review 'Keeping up scientific standards' by Martin Blume (Nature 459, 645-646; 2009), we inadvertently omitted the author's declaration of competing interests, submitted before he was engaged to write the review. This has been restored online at http://tinyurl.com/mwserz. 